\title{
As leituras de textos de divulgação científica feitas por licenciandas no estágio supervisionado em física
}

\author{
Readings of popular science texts done by undergraduates in the supervised practice in physics
}

\author{
Daniele Correia*1, Inés Prieto Schmidt Sauerwein ${ }^{2}$ \\ ${ }^{1}$ Instituto de Química, Universidade Federal de Mato Grosso do Sul, Mato Grosso do Sul, MS, Brasil \\ ${ }^{2}$ Departamento de Física, Universidade Federal de Santa Maria, Santa Maria, RS, Brasil
}

Recebido em 07 de Novembro, 2016. Aceito em 09 de Janeiro, 2017.

\begin{abstract}
Neste artigo, são analisadas as leituras de Textos de Divulgação Científica (TDC) feitas por licenciandas nas disciplinas de Estágio Supervisionado em Ensino de Física II e III. Os registros orais e escritos produzidos durante as atividades com TDC associados às estratégias de leitura, foram analisados à luz dos referenciais teóricos da Análise do Discurso de linha francesa e da área de Educação em Ciências. Constatou-se que, nos estágios de regência, foram valorizadas as leituras polissêmicas, sendo o textopretexto o modo de leitura exercitado nas aulas e o discurso apropriado pelas licenciandas tendeu ao polêmico. Além disso, nas pré-regências, a função atribuída aos TDC se restringiu ao uso do texto para ensinar Física. Nas regências, as atividades com TDC tiveram as funções de promover o desenvolvimento de habilidades relacionadas às expressões oral e escrita dos alunos, à articulação entre o conteúdo de Física e o cotidiano do aluno e despertar atitudes nos alunos. Por fim, infere-se que a proposta do uso de TDC, associado a estratégias de leitura em aulas de Física, é um caminho possível para a valorização das leituras polissêmicas, além de favorecer a formação dos sujeitos-leitores no contexto da formação inicial de professores e na escola.
\end{abstract}

Palavras-chave: Leitura, textos de divulgação científica, ensino de Física, formação inicial, estágio supervisionado.

This article analyzes the readings of Popular Science Texts (TDC) done by undergraduates in the disciplines of supervised internship in Physics Teaching II and III. Oral and written records produced during activities with TDC associated with reading strategies were analyzed according to the theoretical frameworks of the analysis of the French Discourse and Education area science. It was observed that polysemic readings were valued in the teaching stages, in which the text-pretext reading strategy was predominant in classes and the discourse used by the students tended to be controversial. Moreover, in the pre-teaching, the TDC function was restricted to the use of texts in order to teach physics. There was an improvement in classes since TDC included the development of oral expression and written skills on the part of students; the articulation between physics contents and learners' daily life; the awakening of interest and motivation due to curiosity on the part of students. Finally, it is inferred that employing TDCs associated to reading strategies in physics classes point to a possible way for the advancement of polysemic readings, besides encouraging the formation of subject-readers within the context of teachers' training and school.

Keywords: Reading, popular science texts, physics teaching, supervised internship.

\section{Introdução}

A Divulgação Científica (DC), enquanto gênero do discurso, possui características próprias com relação ao tema, ao estilo e à composição [1,2]. Ela está

*Endereço de correspondência: daninhacorreia@gmail.com presente em diversos espaços sociais e meios de comunicação, como, por exemplo, em jornais, livros, revistas, cinema, museus, programas de TV, encartes de revistas, materiais paradidáticos, palestras, espetáculos teatrais, sites da internet, programas de rádio, etc. 1]. Na área de Educação em Ciências, pes- 
quisas recentes apontam a importância da leitura de Textos de Divulgação Científica (TDC) na formação de sujeitos leitores, assim como as potencialidades dos TDC no processo de ensino e aprendizagem de conteúdos científicos [3,4]. Ainda, há trabalhos que sugerem esses materiais como uma poderosa ferramenta didática, cuja principal função é veicular temas sobre ciência e tecnologia em linguagem acessível, sendo destinada a um público não especializado no assunto [1,5-16. Somado a isso, o incentivo à leitura de materiais de DC possibilita ao aluno o acesso a uma maior diversidade de informações, o desenvolvimento de habilidades de leitura, a apropriação de conceitos, formas de argumentação e elementos de terminologia científica [13,17].

Com relação às funções atribuídas à DC nas pesquisas na área de ensino de Física, Ribeiro e Kawamura [18 apontam cinco vertentes: mundo de leitura (a DC favorece o desenvolvimento de habilidades e de hábitos nos alunos); leitura de mundo (a DC favorece o ensino de conteúdos científicos); formação do espírito crítico (a DC contribui para a formação de uma imagem de ciência adequada e crítica, assim como para reflexões sobre ciência, suas aplicações e implicações sociais); contextualização $e$ atualidade (a DC auxilia na contextualização dos conteúdos curriculares, no contato com informações atualizadas sobre ciência e tecnologia, na articulação entre o conteúdo científico e o cotidiano do aluno); olhar da sedução (a DC desperta o interesse por temas científicos, motiva novas leituras, gera atitudes e sentimentos nos leitores - curiosidade, emoção, etc. -, atrai e insere o leitor no mundo da ciência).

O funcionamento das leituras de TDC na formação inicial de professores de Ciências Naturais tem sido tema de poucos estudos na área de Educação em Ciências. Nessa perspectiva, a atenção está voltada principalmente para a investigação de: autoria em textos produzidos por graduandos em Química, a partir de atividades de leitura com TDC [19]; discurso pedagógico em questões sobre TDC, formuladas por graduandos em Química [20; e discursos apropriados por licenciandos em Química durante seus estágios de regência 21,22. Há autores que investigaram as leituras feitas por licenciandos em Ciências Biológicas sobre TDC no contexto de suas regências em seus estágios supervisionados [2].

Além disso, há estudos que identificaram características próprias do discurso da divulgação científica em TDC, produzidos por futuros profes- sores de ciências [23], ou do discurso do jornalismo científico nas respostas de licenciados em Física a um questionário realizado após a leitura de TDC [24]. Somando-se a esses estudos, há pesquisadores que investigaram os sentidos atribuídos por licenciandos à leitura de TDC, a partir da análise das respostas dadas por eles a questionários sobre os textos 15, 16 25. Ainda, encontraram-se pesquisadores que se dedicaram a investigar sobre a predisposição de licenciandos em Física em trabalhar conteúdos de Física Moderna no ensino médio, antes e depois de eles se envolverem em atividades de leitura de TDC [26].

A maioria das pesquisas supracitadas foi realizada de forma pontual e seus resultados enfatizam "os produtos" mediante análises de questionários pré e pós-teste. Ainda, não se percebe explicitamente a preocupação dos autores em investigar as potencialidades das leituras de materiais de DC na formação dos sujeitos-leitores, também, não há menção de que as atividades de leitura propostas nessas pesquisas contemplam as etapas de pré/durante/pós-leitura (SOLÉ, 1998). Entende-se que essa forma de sistematizar as atividades de leitura é fundamental no acompanhamento do processo de funcionamento das leituras de TDC em sala de aula e das aprendizagens dos sujeitos-leitores.

Nesse sentido, defende-se que as leituras de TDC em sala de aula devem ser associadas às atividades estratégicas de pré-leitura, durante a leitura e pósleitura [4]. De acordo com Solé [28], as atividades de pré-leitura têm o intuito de motivar a leitura. Elas devem permitir que o aluno faça previsões e levante hipóteses sobre as informações do texto, bem como estabeleça conexões entre seus conhecimentos prévios e o assunto abordado no texto. As atividades de durante a leitura devem favorecer a retomada das previsões iniciais e a verificação e sistematização do que foi compreendido a partir da leitura do texto. As atividades de pós-leitura devem permitir que o aluno reavalie seus conhecimentos iniciais, estabeleça diferenciação entre o que sabia antes e o que passou a compreender após a leitura do texto, faça vinculação entre as informações do texto e o conteúdo estudado, sintetize as principais ideias/informações do texto. A leitura de TDC associada às atividades estratégicas de pré/durante/pós-leitura favorecem o envolvimento dos alunos durante todo o processo de leitura e discussão do texto. Além disso, as estratégias de leitura podem servir para conduzir a 
discussão articulada entre as informações do TDC e o conhecimento científico e/ou instrumento de avaliação do professor. Esta avaliação se dá mediante as tarefas propostas em cada etapa da leitura e nas quais o docente pode caracterizar e acompanhar a evolução da aprendizagem dos alunos.

Aliás, há carência de pesquisas voltadas à proposição e à avaliação de atividades de ensino que tenham como foco promover a articulação entre a leitura de materiais de divulgação científica e o ensino de conteúdos científicos, mediante uso de estratégias de leitura. Ademais, como ressaltam Almeida e Silva, "as estratégias de leitura como parte do funcionamento mais amplo da linguagem" estabelecem "relações entre os modos como os sujeitos lêem os textos, se relacionam entre si" [27, p. 2/3]. Neste caso, entende-se que o funcionamento das leituras de TDC em sala de aula está diretamente relacionado às estratégias de leitura (ou tarefas) empregadas nos distintos momentos da leitura (atividades propostas na etapa de pré/durante/pós-leitura). Assim, as estratégias de leitura utilizadas em sala de aula pelo professor podem ser fator de influência na atribuição de sentidos que os alunos dão aos TDC.

Somando-se ao exposto, não se encontrou trabalhos que investiguem o funcionamento das leituras de TDC na formação inicial de professores de Física, especialmente, no contexto do estágio supervisionado. Em particular, à carência de pesquisas que investiguem o "processo", isto é, como funcionam as leituras de TDC, feitas por professores em formação, no contexto do estágio profissional. O estudo do "processo" permite investigar com profundidade: o tipo de leitura de TDC realizada, os modos de leitura exercitados, as funções assumidas pelos TDC em aula, as articulações estabelecidas entre o TDC e o conteúdo científico, os sentidos atribuído à leitura e como ocorre o processo de leitura de TDC por parte dos estudantes do ensino médio. Agora, a investigação de todo esse processo, exige comprometimento por parte dos envolvidos, principalmente, do professor formador e do licenciando. Sendo que, o licenciando deve ser devidamente instruído sobre a importância da leitura, usos e escolhas de materiais de DC.

Diante da carência e da relevância de pesquisas voltadas ao acompanhamento do funcionamento de atividades de leitura de TDC associadas à estratégias de pré/durante/pós-leitura, no contexto da formação inicial de professores de Física, o pre- sente artigo tem como objetivo investigar o funcionamento das leituras de TDC, feitas por licenciandas, durante seus estágios de pré-regências $\bigsqcup^{1}$ e regências $\bigsqcup^{2}$. A tentativa é compreender qual(is) tipo(s) de leitura(s) de TDC foi(ram) privilegiada(s) pelas licenciandas no contexto do estágio supervisionado, bem como o(s) modo(s) de leitura exercitado(s) e $\mathrm{a}(\mathrm{s})$ função(ões) assumida(s) pelos TDC em sala de aula. Para tal, Buscar-se-á estabelecer relações entre: quem lê (as licenciandas e suas histórias de leituras), qual(is) tipo(s) de leitura(s) é (são) realizada(s) (parafrásica e/ou polissêmica), como se lê (estratégias de leitura empregadas nas atividades com TDC), modos de leitura (postura de leitura frente ao TDC: leitura-busca-de-informações, leituraestudo-do-texto, leitura-texto-pretexto e leitura-fruição do texto), como expressa o que se lê (discurso pedagógico - autoritário, polêmico e lúdico - apropriado pela licencianda ao colocar a atividade com TDC em funcionamento) e para que se lê (funções atribuídas: mundo de leitura, leitura de mundo, formação do espírito crítico, contextualização e atualidade e olhar da sedução).

Para tal, pretende-se explorar os registros de quatro aulas planejadas e executadas por duas licenciandas (sujeitos de pesquisa) no contexto de seus estágios de pré-regência e regência, desenvolvidos nas disciplinas de Estágio Supervisionado em Ensino de Física II e III do Curso de Licenciatura Plena em Física da Universidade Federal de Santa Maria, localizada no estado do Rio Grande do Sul, Brasil. A análise dos registros é baseada nos referenciais teóricos da Análise do Discurso de vertente francesa e da área de Educação em Ciências.

\section{O Significado da Leitura na ótica da Análise de Discurso}

Neste trabalho, leitura é entendida como atribuição de sentidos e não como mera decodificação da palavra. Esta acepção vai ao encontro da perspectiva de leitura para o ensino de Ciências Naturais, atualmente defendida por pesquisadores da área de Educação em Ciências [2, 29], a qual tem como aporte teórico a Análise do Discurso Francesa (AD),

\footnotetext{
${ }^{1} \mathrm{O}$ termo pré-regência é empregado para identificar o período do estágio em que as licenciandas ainda não assumiram as turmas do ensino médio.

${ }^{2} \mathrm{O}$ termo regência é adotado para identificar o momento do estágio em que as licenciandas assumiram as turmas do ensino médio.
} 
baseada na obra de Michel Pêcheux, cujo desdobramento no Brasil se deu por meio de trabalhos de Eni Orlandi.

Assim sendo, a leitura, enquanto um ato de ler, prevê interação entre autor-texto-leitor, na qual interferem, entre outros aspectos, as experiências de vida, as histórias de leitura, os valores, as crenças, as relações intertextuais (isto é, tecer relações com textos lidos anteriormente), conhecimentos prévios do leitor, o nível de proximidade deste leitor com o texto, os objetivos da leitura [30], o contexto histórico e social da produção do texto. A leitura, quando assumida nessa perspectiva discursiva, deve ser considerada como uma questão de condições, de modos de relação e de produção de sentidos.

Agora, quando se pensa especificamente na leitura de um mesmo texto (oral ou escrito), é possível que ele seja interpretado de distintas maneiras por diferentes leitores, e a explicação para isto reside no fato de ser próprio da natureza da linguagem a possibilidade da multiplicidade dos sentidos. Assim, nota-se a existência de textos que proporcionam um tipo de leitura chamada parafrásica, ou seja, que "se caracteriza pelo reconhecimento (reprodução) do sentido dado pelo autor", enquanto outros se abrem à possibilidade de uma leitura polissêmica, que "se define pela atribuição de múltiplos sentidos ao texto" 33. p. 187]. As leituras polissêmicas acontecem por conta dos deslocamentos de sentidos que são possíveis devido ao fato de o sentido não se encontrar inscrito no texto, existindo, portanto, a possibilidade de diferentes interpretações por distintos sujeitos [34].

Nessa direção, Orlandi 32 sugere que as produções dos diferentes discursos (autoritário, polêmico e lúdico) se fazem na articulação entre a paráfrase (produção de um único sentido) e a polissemia (possibilidade de produção de múltiplos sentidos). Assim, o discurso autoritário é o que tende para a paráfrase, sendo a polissemia contida, o referente apagado pela relação de linguagem que se estabelece, e o locutor se coloca como agente exclusivo, apagando também sua relação com o interlocutor. No discurso polêmico, aquele em que a polissemia é controlada, o referente é disputado pelos interlocutores, os quais se mantêm presentes, numa relação tensa de disputa pelos sentidos. O discurso lúdico, por sua vez, é aquele em que a polissemia está aberta, o referente está presente como tal, sendo que os interlocutores se expõem inteiramente aos efeitos dessa presença, não regulando sua relação com os sentidos.
Orlandi [33 p.3] define o Discurso Pedagógico (DP) como autoritário em seu funcionamento, pois na instituição de ensino o professor é a autoridade e detém conhecimento; portanto, idealmente, ele "possui o saber e está na escola para ensinar, o aluno não sabe e está na escola para aprender." Logo, no contexto da sala de aula, professores e alunos dizem determinadas coisas e outras não, produzem determinados sentidos e outros não. Desse modo, a autora propõe que, para interferir no caráter autoritário do DP, é preciso atingir seus efeitos de sentido, torná-lo um discurso polêmico, e isso, da parte do professor, exigiria elaborar seu próprio texto, seu discurso, expor-se a efeitos de sentidos múltiplos e deixar espaço para a existência do ouvinte (aluno) como sujeito ativo. Já da parte do aluno, implicaria posicionar-se criticamente durante o processo de leitura do texto, isto é, constituir-se como ouvinte e construir-se como autor na dinâmica de interlocução.

Andrade e Martins [36] investigaram um grupo de professores de Física, Química e Biologia de uma escola federal de Ensino Médio. Utilizando a Análise de Discurso de linha francesa, os autores analisaram os sentidos, os conceitos e as concepções de leitura, explicitados nos discursos dos docentes entrevistados. Nesse estudo, os autores destacam que parece haver uma associação entre o tipo de discurso pedagógico e certo modo de ler, no qual, aos textos didáticos e/ou científicos, são atribuídos sentidos únicos e a leitura adquire um caráter de busca e assimilação de informação. Acredita-se que não haja uma única maneira de se ler um texto, mas possibilidades de modos de interação entre autor-texto-leitor, que são conduzidos por estratégias de leitura (escolhidas e definidas pelo sujeito consciente de seu papel de leitor).

Uma importante contribuição sobre a relação entre texto e leitor vem dos trabalhos de Geraldi 37 . e Souza [38], nos quais os autores apontam quatro modos de leitura que podem ser exercitados pelo leitor: 1) A leitura - busca de informações - quando o objetivo do leitor é a busca de informações. Assim, o que define a interlocução que se estabelece neste processo de leitura é justamente seu objetivo - a extração de informações do texto. Este tipo de leitura está associado à finalidade de ler este ou aquele texto, buscar esta ou aquela informação. 2) A leitura - estudo do texto - este tipo de leitura pode envolver formas variadas de interlocução lei- 
tor/texto/autor, abrangendo, por exemplo, o estudo dos objetivos, do assunto, dos argumentos e contraargumentos, etc. Além disso, a leitura de estudo do texto visa à aquisição de informações que são utilizadas para aprofundar e/ou desvendar aspectos relacionados ao cotidiano, à ciência, dentre outros. 3) A leitura do texto - pretexto - nesse tipo de leitura o que importa é o pretexto, ou seja, a atividade a ser realizada a partir da leitura, que definirá o tipo de interlocução que se estabelece entre o leitor e o texto. A leitura texto-pretexto pode propiciar a intertextualidade, isto é, quando os leitores se remetem a outros textos para aprofundar seus conhecimentos e/ou argumentar sobre determinado assunto. 4) $A$ leitura - fruição do texto - é aquela na qual a interlocução do leitor com o texto se estabelece pelo prazer de ler. O leitor lê com o intuito de aprender e de buscar informações para compreender o mundo em que vive.

Somando-se ao exposto, Nascimento e Cassiani [2], Teixeira Junior e Silva [39], Andrade e Martins [36 e Souza e Nascimento 29 têm destacado a necessidade de reflexões, na formação inicial de professores, sobre a responsabilidade do professor de Ciências Naturais na formação do leitor, ressaltando a importância da compreensão de leitura como atribuição de sentidos e, portanto, da não petrificação de leituras previstas nos textos (os sentidos esperados pelo professor devem ser trabalhados como um dos constituintes da produção do texto, mas não deve ser o "único" sentido constituinte). Isto significa dizer que os formadores de professores devem discutir com os licenciandos sobre o verdadeiro significado do papel da leitura no ensino e aprendizagem de Ciências, no sentido de discutir, propor e avaliar estratégias, que visem preparar o futuro professor para sua função de formador de leitores no ensino médio, a fim de o licenciando, no contexto de sua regência em sala de aula, crie um ambiente que estimule o gosto pela leitura, a discussão articulada entre o conteúdo científico e o texto, valorizando não somente leituras parafrásicas, mas também as polissêmicas.

\section{Aspectos metodológicos}

A pesquisa desenvolvida, quanto a sua abordagem, é predominantemente qualitativa ou naturalística 40 e caracteriza-se como uma pesquisa participante 41, 42.
Os sujeitos participantes foram duas licenciandas, Beatriz e Mariana, que nos anos de 2013 a 2015, cursaram as quatro disciplinas que constituem o estágio profissional do curso de Física Licenciatura da UFSM, Estágio Supervisionado em Ensino de Física (ESEF) I, II, III e IV.

No primeiro dia de aula da disciplina de ESEF I, apresentou-se, às professoras em formação, as atividades previstas para cada uma das quatro disciplinas do ESEF, destacando-se que algumas das aulas a serem ministradas pelas licenciandas (em seus os estágios de pré- regência e regência) envolveriam uso de TDC.

Para subsidiar os planejamentos dessas aulas com TDC, a pesquisadora (primeira autora deste artigo) ofertou às licenciandas a oficina "Leitura e escrita nas aulas de Física". A oficina foi realizada em seis encontros semanais de três horas de duração (de março a abril/2014) e contemplou leituras e discussões de trabalhos de eventos, de artigos e de capítulos de livros voltados ao ensino de Física e/ou à questão da leitura, à escolha e ao uso de estratégias de pré/durante/pós-leitura para trabalhar textos em sala de aula. Após concluir a oficina, foi solicitado que as licenciandas elaborassem aulas envolvendo uso de TDC e as incluíssem em seus planejamentos semestrais de ensino. Para tanto, as licenciandas foram orientadas a utilizar textos de revistas (Ciência Hoje, Scientific American Brasil, Superinteressante, dentre outras), jornais e/ou de sites de notícia (O Globo, Folha de São Paulo, BBC Brasil, etc.). As licenciandas tiveram liberdade de escolher os TDC, sendo acordado, como critério de seleção que, eles estivessem em consonância com os conteúdos de Física a serem trabalhados. Após o término da oficina, as licenciandas ministraram suas aulas com TDC na universidade e nas escolas.

As licenciandas foram autorizadas a ministrar as aulas com TDC em suas escolas somente após terem realizado a aula simulada ${ }^{3}$ e apresentado uma versão revisada do planejamento na reunião de ori-

\footnotetext{
3 As aulas simuladas tinham como objetivo simular o desenvolvimento das aulas com TDC a serem implementadas nas escolas. Essas aulas contaram com a participação das professoras orientadoras e das licenciandas, tendo duração de duas horas cada. As aulas simuladas foram gravadas em áudio e vídeo e aconteceram nos meses de maio a novembro de 2014, na universidade. Ao término de cada aula, as licenciandas faziam uma autoavaliação oral e, após essa etapa, as professoras destacavam aspectos que poderiam ser inseridos e/ou aperfeiçoados tanto no plano de aula quanto na postura pedagógica da licencianda.
} 
entação de estágio. No período de pré-regência, cada licencianda implementou, na escola, uma aula com TDC. Já no período de regência, Mariana ministrou duas aulas e Beatriz quatro aulas envolvendo uso de TDC. Para o presente artigo, selecionaram-se a primeira e a última aula envolvendo uso de TDC, ministradas por cada licencianda no período de préregência e regência, respectivamente. Assim sendo, as quatro aulas que serão analisadas estão dispostas no Quadro 1 em negrito, identificando-as de Aulas na Escola 1-AE (período de pré-regência) e 2-AE (período de regência). Entende-se que as análises dessas aulas possibilitam compreender as leituras feitas pelas licenciandas, os discursos produzidos por elas, os modos de leitura exercitados e as funções assumidas pelos TDC em sala de aula.

Neste trabalho, são analisados os registros orais e escritos produzidos pelas licenciandas nas implementações das atividades de ensino com TDC desenvolvidas nos períodos de pré-regência e regência dos estágios (ver Quadro 1), em particular, nos dois semestres do ano de 2014, em que elas cursaram as disciplinas de ESEF II e III, respectivamente. No contexto da escola, as fontes de dados de pesquisa são oriundas dos registros das aulas com TDC ministradas pelas licenciandas e observadas pela pesquisadora. Tais fontes são: Diários da Prática Pedagógica (DDP) Diários de Pesquisa (DP) ${ }^{5}$ e gravações das aulas em áudio. Já no contexto da universidade, as fontes de dados englobaram os registros das aulas simuladas (planos de aula, gravações das aulas em áudio e vídeo, DPP e DP) e os registros das reuniões individuais e semanais de orientação do estágio ou atendimento ${ }^{6}$ (entrevistas, gravações em áudio e $\mathrm{DP})$. Os dados foram analisados à luz dos referenciais teóricos da Análise do Discurso de vertente francesa e da área de Educação em Ciências.

\footnotetext{
$\overline{4}$ São os diários produzidos pelas licenciandas para cada aula ministrada. Nesses documentos, elas registraram a descrição e avaliação crítica-reflexiva do trabalho didático-pedagógico realizado em sala de aula 46,47 .

${ }^{5}$ São os diários produzidos pela pesquisadora. Nesse documento, registraram-se as observações feitas durante o processo de organização, execução e avaliação das aulas que envolveram o uso de TDC 48.

${ }^{6}$ Nos atendimentos (ou reuniões de orientação de estágio), discutiam-se as atividades desenvolvidas por cada licencianda nos distintos momentos do estágio (pré-regência, regência e pós-regência). Esses encontros ocorriam semanalmente e duravam cerca de uma hora cada.
}

\subsection{As licenciandas e as turmas: as condições de produção das aulas}

Mariana, quando iniciou o ESEF I, estava no $7^{\mathcal{O}}$ semestre, e Beatriz, em termos de disciplinas cursadas, no $5^{\circ}$ semestre do curso. Em entrevistas realizadas individualmente no dia 05/09/13, as licenciandas foram inqueridas sobre seus hábitos de leitura. Mariana relatou ler raramente, e Beatriz comentou ler, diariamente, reportagens (em sites de notícias, revistas e/ou jornais impressos) sobre assuntos polêmicos amplamente divulgados na imprensa. Ambas as licenciandas destacaram que não costumavam realizar, espontaneamente, buscas e leituras de textos que abordassem assuntos relacionados à Física, justificando que essas leituras não eram prazerosas. Além disso, Mariana e Beatriz mencionaram que até aquele estágio da graduação não haviam se envolvido em atividades de ensino de Física com TDC.

Com relação à iniciação à docência, Mariana e Beatriz estagiaram em turmas da segunda série do ensino médio de escolas públicas, localizadas no município de Santa Maria, no estado do Rio Grande do Sul. As licenciandas desenvolveram suas regências entre os meses de agosto e dezembro de 2014, sendo que Mariana ministrou 30 aulas (duas aulas semanais de $45 \mathrm{~min}$ ) e Beatriz ministrou 45 aulas (três aulas semanais de $45 \mathrm{~min}$ ). Mariana e Beatriz relataram em seus DPP que as turmas tinham em média 25 alunos, os quais, em sua maioria, eram participativos.

\section{Análise e Discussão das Atividades de Ensino de Física com TDC Desenvolvidas no Estágio Supervisionado}

\subsection{As pré-regências}

\section{Aula 1-AE - Mariana}

A atividade didática com o texto "Matéria Malcomportada" foi desenvolvida em duas aulas e contou com a presença de 25 alunos. As aulas contemplaram as seguintes etapas:

\footnotetext{
Etapa 1 (16/07/2014) - Primeiramente foram feitos questionamentos iniciais [...]. Etapa 2 (16/07/2014) - Foi mostrado aos alunos uma imagem [...] e o título do texto "Matéria malcomportada". Em seguida, foi entregue aos mesmos as seguintes questões [...].
} 
Quadro 1: Resumo das principais informações das aulas com TDC selecionadas e ministradas pelas licenciandas em suas pré-regências e regências nas $2^{\mathrm{a}}$ séries do ensino médio.

\begin{tabular}{|c|c|c|c|}
\hline $\begin{array}{l}\mathscr{0} \\
\tilde{0} \\
\text { Z }\end{array}$ & $\begin{array}{l}\text { Aula Simulada (AS) ou } \\
\text { Aula na escola (AE)/ } \\
\text { Pré-Regência ou Regência }\end{array}$ & Tema da aula & TDC \\
\hline \multirow{2}{*}{ 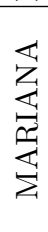 } & 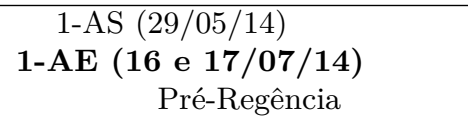 & Dilatação Térmica & $\begin{array}{c}\text { Matéria Malcomportada: quando o } \\
\text { fenômeno físico contraria a } \\
\text { intuição } 43\end{array}$ \\
\hline & $\begin{array}{r}2-\mathrm{AS}(19 / 11 / 14) \\
\mathbf{2 - A E}(\mathbf{2 8 / 1 1 / 1 4 )} \\
\text { Regência }\end{array}$ & $\begin{array}{l}\text { Qualidades } \\
\text { fisiológicas do Som }\end{array}$ & Para ouvir melhor 44 \\
\hline \multirow{2}{*}{ 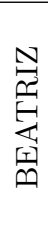 } & $\begin{array}{r}\text { 1-AS }(04 / 06 / 14) \\
\text { 1-AE (04/07/14) } \\
\text { Pré-Regência }\end{array}$ & Viscosidade & $\begin{array}{l}\text { Sobre sangue, café, óleo e... coletes à } \\
\text { prova de bala } 45 .\end{array}$ \\
\hline & $\begin{array}{r}\text { 2-AS }(19 / 11 / 14) \\
\mathbf{2 - A E ~ ( 2 8 / 1 1 / 1 4 )} \\
\text { Regência }\end{array}$ & $\begin{array}{l}\text { Qualidades } \\
\text { fisiológicas do Som }\end{array}$ & Para ouvir melhor 44 \\
\hline
\end{tabular}

Etapa 3 (16/07/2014) - [...] os alunos foram orientados a ler individualmente o TDC [...]. Durante a leitura os alunos destacaram trechos que acharam importantes e também assinalaram suas dúvidas [...].

Etapa 4 (17/07/2014) - Na aula os alunos foram divididos em grupos e orientados a elaborarem duas questões. Estas foram recolhidas e redistribuidas entre os grupos, [...] os alunos foram orientados a responder as questões recebidas [...]. Ao término desta etapa foi feita a explicação do assunto utilizando trechos destacados pela estagiária e trechos/dúvidas dos alunos [...]. (Mariana em trabalho apresentado no XXI SNEF, 2015)

Durante a realização das Etapas 1, 2 e 3, o discurso de mariana tendeu ao polêmico, ela estimulou os alunos a discutir as questões propostas e ainda os incentivou a levantarem hipóteses sobre o assunto que seria discutido no TDC. Na Etapa 4, após os alunos terem realizado a tarefa proposta, Mariana solicitou que um integrante de cada grupo lesse a resposta dada à questão proposta. Como não houve voluntários, Mariana questionou os alunos: "Sobre o que o texto trata? O que vocês responderam na tarefa?". Nesse momento, os representantes dos grupos comentaram:

O texto discute sobre o comportamento de alguns materiais frente a uma mudança de temperatura.

O comportamento anômalo depende da temperatura $[. .$.$] .$
Materiais malcomportados e suas aplicações tecnológicas [...]. (Trechos da aula registrada em áudio)

Certamente, este seria o momento oportuno de se colocar em prática o que estava previsto em seu plano de aula explicitado nas palavras de Mariana: "utilizar a dinâmica de leitura para articular o conhecimento Físico às informações apresentadas pelos alunos a partir das leituras feitas do TDC (Mariana em seu plano de aula - 02/07/14)". No entanto, Mariana simplesmente fez um movimento com a cabeça confirmando que as respostas estavam corretas e interrompeu em definitivo a dinâmica de leitura proposta. Destaca-se que Mariana apresentou este mesmo comportamento na aula simulada (realizada em 29/05/14). A licencianda, ao perceber que seus alunos apresentaram interpretações alternativas àquelas que ela havia previsto para o TDC, preferiu interromper a dinâmica de leitura e expor o conteúdo de forma tradicional, desconsiderando as interpretações dos alunos. O discurso autoritário apropriado pela licencianda privilegiou somente as leituras parafrásicas, sendo que o texto foi utilizado para buscar informações que explicassem o caso específico de comportamento anômalo da água e/ou para destacar outros exemplos de materiais (os mesmos abordados no TDC) que apresentam comportamento irregular em determinadas temperaturas, abordando suas aplicações tecnológicas. Com isso, a licencianda, atribuiu ao TDC função de leitura de mundo 18, em que o texto foi utilizado para o ensino de conteúdos de Física.

No atendimento realizado em 23/07/14, Mariana justifica seu comportamento apresentado aula mi- 
nistrada na escola: "[...] achei que não daria tempo, optei por focar no conteúdo de dilatação anômala, até porque estava tudo escrito no TDC, já com o exemplo da água [...]". Constata-se que a licencianda previa uma única leitura (a considerada óbvia e correta por ela) do TDC e, portanto, a polissemia para ela é algo que não é considerado. Esse modelo de leitura de sentido único autorizado pela licencianda, no qual o sentido do texto precedeu as leituras feitas pelos estudantes, também foi observado no trabalho de Nascimento e Cassiani [2], em que as autoras verificaram que licenciandos em Ciências Biológicas apresentaram leituras de TDC de sentido único, nas primeiras aulas ministradas, durante as regências de estágio.

\section{Aula 1-AE - Beatriz}

Nessa aula, Beatriz utilizou o TDC "Sobre sangue, café, óleo e...coletes à prova de bala", realizada no dia 04/07/14 (duração de $90 \mathrm{~min}$ ), com a presença de 17 alunos. A aula contemplou as seguintes etapas:

\begin{abstract}
Etapa 1: Iniciou-se a aula mostrando aos alunos o título do TDC "Sobre sangue, café, óleo e... coletes à prova de bala". A seguir foram colocados [...] questionamentos aos alunos [...]. Etapa 2: Foi solicitado que os alunos lessem o texto e durante a leitura anotassem suas dúvidas. Etapa 3: Após a leitura do TDC, os alunos foram divididos em duplas (totalizando 8 duplas) e cada dupla elaborou um título para os parágrafos previamente selecionados pela estagiária. Etapa 4: Discussão dos títulos propostos pelos grupos, dúvidas do TDC destacadas pelos alunos e introdução do assunto viscosidade a partir de trechos do texto [...]. (Beatriz em trabalho apresentado no XXI SNEF, 2015)
\end{abstract}

Durante a realização das três primeiras etapas, os alunos demonstraram curiosidade, participaram bastante e discutiram entre eles algumas hipóteses acerca do tema do TDC. Na Etapa 4, os alunos leram as frases elaboradas para os parágrafos prédeterminados. Foi possível perceber que algumas dessas sínteses apresentavam literalmente as ideias do autor, outras sintetizavam, com palavras distintas, as mesmas ideias originalmente proferidas pelo autor, e uma minoria mostrou produções próprias. Destaca-se que esse momento da aula seria o ideal para se colocar em ação a atividade prevista no plano de aula de Beatriz, que era utilizar as interpretações dos alunos (presentes nas frases-síntese) para promover a discussão e articulação do TDC à abordagem do conteúdo de viscosidade. Contudo, isso não ocorreu na prática. Beatriz, frente àquelas produções inesperadas dos alunos e movida pelo que, possivelmente, já havia projetado para aquela aula, optou por não fazer as necessárias e previstas intervenções (conforme registrado em seu plano de aula). Após alguns alunos terem realizado a leitura de suas sínteses, Beatriz interrompeu a dinâmica e conduziu a explicação teórica acerca da dependência da viscosidade de um fluido com a temperatura e com as forças intermoleculares.

Neste momento da aula a explicação do conteúdo se deu de forma bem direcionada por parte da licencianda. O discurso adotado, na maior parte do tempo, tendeu para o autoritário. Isto é, ela conduziu a discussão com poucas perguntas e selecionando apenas as informações apresentadas pelos alunos que poderiam ser utilizadas na explicação, revelando que a leitura valorizada por Beatriz foi a parafrásica, em que a licencianda utilizou o texto para buscar informações que seriam úteis para explicar o conteúdo de viscosidade. Assim, Beatriz utilizou o TDC com a finalidade de ensinar os conteúdos de Física, autorizando a função do TDC como leitura de mundo.

No atendimento realizado em 09/07/14, inqueriuse Beatriz sobre a forma como ela conduziu a Etapa 4, ela argumentou que: "[...] tinha planejado introduzir o conteúdo junto com os parágrafos [...] acho que não consegui lidar com a falta de interpretação própria dos alunos sobre o texto [...] resolvi interromper a dinâmica e passar o conteúdo a partir de alguns trechos do TDC. Agora vejo que falhei, mas não estava preparada para isso naquele momento [...]".

Sobre as aulas ministradas por Mariana e Beatriz na escola no período de pré-regência, pode-se inferir que houve avanços significativos quando comparadas às aulas simuladas ministradas na universidade no que tange à exposição dos conteúdos físicos, à postura didático-pedagógica e à escolha das tarefas de pré/durante/pós-leitura. Contudo, no contexto das aulas ministradas na escola, prevaleceram as leituras parafrásicas e a dificuldade de utilizar as tarefas de leitura propostas e/ou outras estratégias de leitura para promover a discussão e articulação entre as informações dos TDC e os conteúdos de Física previstos. Isso significa que as tarefas de leitura, no 
contexto dessas aulas, foram realizadas pelos alunos em sua totalidade e na sequência prevista, mas não atingiram seu o objetivo principal que era de interligá-las (tarefas de leitura) às discussões em aula. Por último e, não menos importante, as licenciandas não valorizaram as interpretações múltiplas realizadas pelos alunos durante as discussões em sala.

As dificuldades em trabalhar com TDC apresentadas pelas licenciadas em seus estágios de préregência podem ser justificadas, pela falta de leitura de materiais de DC, pela inexperiência em trabalhar com DC em aulas de Física, por problemas de domínio de conteúdo e, também, pelo fato de ser a primeira experiência prática das licenciandas, frente aos alunos do ensino médio, com esse tipo de recurso didático. Estes fatores somados interferiram na desenvoltura delas em sala de aula, conforme os relatos:

Eu estava nervosa, minha maior preocupação era como ia acontecer a aula com TDC [...], foi difícil esta experiência, pois tinha a questão de nunca ter visto em outras disciplinas da graduação ninguém trabalhar com um TDC desta forma, em uma aula de Física [...].Também tem a questão de que não foi fácil falar do comportamento irregular de outros materiais, sendo que eu só fui saber disso, de que existiam outros exemplos além da água, por meio da leitura do TDC [...]. (Mariana em atendimento realizado$23 / 07 / 14)$

[...] não foi uma tarefa fácil, enquanto aluna, tanto no ensino médio, como na graduação, nunca tive uma aula de Física que trabalhava com TDC [...]. Para trabalhar com texto o professor precisa dominar totalmente o conteúdo, estar seguro e não ter dúvidas, $e$ isso não aconteceu comigo, pois eu não me preparei o suficiente [...]. (Beatriz em seu diário da prática pedagógica-09/07/14)

É importante destacar que as atividades com TDC implementadas pelas licenciandas no período de préregência contribuíram, de um lado, para que elas vivenciassem na prática como é ministrar uma aula de Física com esse tipo de recurso didático, bem como refletissem sobre a sua atuação (dificuldades e superações) e sobre as potencialidades das leituras de TDC nas aulas de Física. Por outro, sinalizaram a necessidade da adoção de medidas, por parte das professoras orientadoras, que viessem a preparar melhor as licenciandas para a sequência de atividades com TDC que seriam executadas por elas nos estágios de regência.

Assim, combinou-se com as licenciandas que as reuniões passariam a englobar a discussão do TDC, do conteúdo e das atividades propostas para cada etapa de leitura do mesmo. Essa nova configuração dada aos atendimentos fez com que as licenciandas estudassem com antecedência o TDC e o conteúdo específico a ser trabalhado a partir dele. Consequentemente, elas passaram a se preparar- melhor para a execução das aulas na universidade e na escola.

Com o passar do tempo, percebeu-se, incialmente, uma mudança na postura de leitura de Beatriz, isto é, ela passou a utilizar as estratégias trabalhadas na oficina de leitura (ofertada na disciplina de ESEF II) para ler o TDC e estabelecer ligações com o conteúdo de Física a ser trabalhado em sala de aula.

Nas três últimas atividades com TDC desenvolvidas por Beatriz na regência, observou-se que, durante a discussão do TDC em sala de aula, a licencianda começou a levar em consideração as questões e/ou dúvidas dos alunos, as repostas dadas às tarefas pré-leitura e, ainda, passou a acrescentar a essa discussão algumas perguntas e trechos do TDC pré-selecionados por ela e que tinham o intuito de fomentar as discussões e/ou promover a articulação entre o conteúdo que estava sendo estudado e as informações do TDC. Beatriz, no atendimento realizado em 04/11/14, comentou sobre seus avanços e sobre os fatores que contribuíram para seu melhor desempenho:

Beatriz: Até o TDC sobre Calorias [primeiro
texto implementado na regência] eu pensava
que o texto era autoexplicativo, eu pensava
que não tinha por que eu ficar falando de
novo, afinal já estava claro no TDC [...]. No
fim, eu reproduzia a maneira errada como
eu sempre li. Então, agora eu percebo que o
texto não tem sentido se o professor não pro-
mover a relação entre o TDC e o conteúdo
[...]. Agora estou me preparando de forma di-
ferente, faço um guia, uma espécie de roteiro
que eu consulto em momentos oportunos da
discussão.
Pesquisadora: E como você constrói esse
guia?
Beatriz: Primeiro eu estudo o TDC. Du-
rante a leitura procuro destacar trechos que
eu poderia fazer o gancho com o conteúdo de
Física, depois estudo o conteúdo e por último 
faço um resumo sobre tudo que eu vou abordar naquela aula, sendo que, em cada parte deste resumo que tem relação com o TDC eu anoto 'ver trecho tal ou pergunta tal que está na página tal do TDC'. Essa espécie de modelo eu não tinha feito para os textos anteriores [...]. Então, o que mudou foi que eu consegui dar o meu olhar para o TDC [...]. (Trechos do atendimento realizado em 04/11/14 e registrado em áudio)

Constatou-se que a licencianda, ao criar seu próprio modelo de trabalho e aplicá-lo em sala de aula, passou a valorizar as múltiplas interpretações dos alunos, e, como consequência, os discursos apropriados pela licencianda (tenderam ao polêmico), os modos de leitura (passou a exercitar a leitura texto-pretexto) e as finalidades atribuídas aos TDC (observou-se que o TDC assumiu mais de uma função em uma mesma aula) foram distintas daquelas verificadas na pré-regência.

Isso só foi possível porque Beatriz percebeu que o TDC não é "autoexplicativo", ou seja, ela percebeu que ele não tem a função de contemplar a explicação de conteúdos científicos. Esta é tarefa do professor enquanto leitor e formador de leitores: exercitar, promover e estimular a interligação entre as informações do TDC e o conteúdo que está sendo ensinado. Nesse sentido, ao relembrar suas histórias de leitura - "eu reproduzia a maneira errada como eu sempre li" -, dá indícios que percebeu que o ato de ler prevê interação entre autor-texto-leitor 30 . Ou seja: aceitou que quem atribui sentidos ao texto é o leitor no momento da leitura em determinado contexto social e histórico, indo ao encontro do que é proposto por Orlandi (2002). A mudança na concepção de leitura de Beatriz fica evidente quando ela constata: "o que mudou foi que eu consegui dar o meu olhar para o TDC".

Esse modo diferenciado de trabalhar o TDC em sala de aula adotado por Beatriz contribuiu para que Mariana também modificasse sua dinâmica de trabalho a partir da primeira atividade com TDC desenvolvida no período de regência em sala de aula. Nas palavras de Mariana:

\footnotetext{
Nesta aula [se referindo à primeira atividade com TDC implementada na regência] tive um melhor desempenho do que aquela ministrada na pré-regência. Acho que o fato de ter tido uma experiência anterior, de conhecer melhor como usar este recurso e ter assistido
}

as aulas simuladas da colega Beatriz dadas no estágio, foram fatores que contribuíram para meu melhor desempenho. (Mariana em seu DPP-19/11/14)

Ao comparar os registros das aulas com TDC ministradas por Mariana nas pré-regência e regência de estágio, foi possível constatar que os avanços foram notáveis naquelas aulas ministradas nas regências (detalhado a seguir na próxima seção 4.2). Por ora, antecipa-se que a forma como Mariana passou a utilizar as tarefas e/ou estratégias de leitura para promover a discussão do TDC e estabelecer relações entre ele e o conteúdo de Física foi similar à adotada por Beatriz em suas aulas de regência de estágio.

\subsection{As regências}

Nesta seção, analisam-se as aulas 2-AE de Mariana e Beatriz, em que ambas adotaram o mesmo TDC. Assim optou-se por destinar o horário da aula simulada (realizada 19/11/14) para discussão dos planejamentos dessas aulas. As implementações nas escolas aconteceram no dia 28/11/14, sendo que somente a aula ministrada por Beatriz foi observada e gravada em áudio pela pesquisadora.

A partir do relato e da análise das aulas 2-AE, pretende-se exemplificar a forma como Beatriz e Mariana passaram a conduzir as atividades com TDC em sala de aula.

\section{Aula 2-AE-Beatriz}

Essa aula foi realizada por Beatriz no dia 28/11/14, teve duração de 90 minutos e contou com a participação de 17 alunos. Sobre o planejamento dessa aula, Beatriz escreveu em seu relatório:
Vou iniciar a aula com alguns questiona- mentos: 1) Como os sons chegam aos nossos ouvidos? 2) Ouvir música com fones de ou- vido é prejudicial a saúde? Por que? 3) Você costuma ouvir música com fones de ouvido? 4) Que altura vocês costumam ouvir música? Qual modelo de fone você utiliza? 5) Que critérios você utiliza na hora de escolher um fone de ouvido? [...].
[...] vamos discutir as respostas dadas a es- sas $[\ldots]$
Em seguida vou entregar e solicitar que os alunos leiam o texto "Para ouvir melhor" $e$ anotem a ideia central do texto e as dúvidas. Após a leitura, [...] cada grupo de alunos deverá escolher um dos modelos de fone de ouvido citados no texto, produzir uma 
propaganda e em seguida apresentar para a turma.

[...] enquanto ocorre a apresentação dos grupos, também vamos discutir as interpretações do texto feitas pelos alunos e, ao mesmo tempo, vou abordar as qualidades fisiológicas do som, como: espectro sonoro, altura, timbre, intensidade, interferência e ruído [...].

(Beatriz em seu relatório de ESEF III)

Na etapa de pré-leitura, momento em que Beatriz discutiu as questões iniciais com os alunos, observouse que ela dialogou com os alunos, incentivando-os a expressarem suas opiniões sobre o uso e as escolhas dos fones. A licencianda, em alguns momentos dessa discussão, apropriou-se de um discurso autoritário para recapitular assuntos estudados em aulas anteriores

Após a leitura do TDC, Beatriz questionou os alunos acerca de suas interpretações sobre o texto, conforme se evidencia no excerto abaixo:

Beatriz: Pessoal! Terminaram? Vamos começar? $O$ que você entenderam sobre o texto? Quais são as ideias principais?

Aluno 3: Que os fones são presença obrigatória na mochila dos jovens [...].

Alguns alunos: $O$ que ele [se referindo a A3]

falou? Não é essa a ideia central!

Beatriz: Pessoal! Vamos respeitar a opinião do colega!

Aluno 6: É, mas o problema é que ele não falou o que interpretou do texto e sim o que tem no texto, né? Tem um trecho do texto que é fala exatamente isto, que os fones [....].

Beatriz: $O$ que mais vocês colocaram?

Aluno 19: [...] mostrar aos jovens como os fones de ouvido podem ser prejudiciais [...] porque depende de quanto tempo você usa o fone de ouvido [...]. Fala sobre os diferentes tipos de fone e como escolher o ideal. Aprendi algumas coisas novas sobre o fone in-ear que uso, [...] percebi que estou usando demais o fone [...]. (Trechos da aula de Beatriz em 28/11/14)

Essa sequência discursiva ilustra bem os avanços, de Beatriz e seus alunos, com relação à leitura e à interpretação dos TDC nas aulas de Física. Como pode ser verificado no excerto acima, os alunos parecem ter compreendido que a síntese da ideia principal é o resultado do diálogo interativo entre as ideias do autor e do leitor [28], o que fica evidente no argumento do Aluno 6, apresentado após o Aluno 3 ter lido sua síntese. Ao longo das implementações das atividades com TDC no período de regência, constatou-se que os alunos utilizaram as estratégias de leitura exercitadas por Beatriz em sala de aula. Em seu diário, Beatriz destaca suas percepções com relação aos seus avanços e dos alunos:

Observei que os alunos já estão habituados
as atividades de leitura e escrita [...] eles
conseguem sintetizar com as próprias pala-
vras as ideias principais do TDC, também
conseguem extrair do texto informações im-
portantes para a vida deles e que possuem
relação com o conteúdo [...], trazer tudo isso
para a discussão em sala[...].
Acredito que essa evolução seja consequência
da sequência de atividades com textos de di-
vulgação científica que tenho levado para a
sala de aula ao longo desse semestre e da
forma como passei a utilizar as estratégias
de leitura para conduzir as discussões em
sala. Além disso, creio que essa evolução foi
conjunta. Da mesma forma que os alunos
evoluíram na questão da leitura, eu também
evolui a medida que essas aulas foram acon-
tecendo[...]. (Beatriz em seu DPP-02/12/14)

Beatriz reconhece em seu depoimento que a mudança na postura de leitura, apresentada por ela e seus alunos, ocorreu gradativamente a medida que as atividades de leitura foram sendo desenvolvidas em sala de aula. Nesse sentido, corrobora-se com Souza e Nascimento [29] sobre a importância de se trabalhar com o professor em formação: as questões da "não transparência da linguagem" e da "desnaturalização da leitura". Cabe salientar que, no contexto das regências de estágio, houve a valorização, por parte das licenciandas, não só das leituras parafrásicas, mas também das polissêmicas, foi um processo lento e que precisou ser estimulado por meio de ações efetivas (práticas de leitura e de escrita) no âmbito do estágio supervisionado. Além disso, foi necessário que as licenciandas repensassem sobre suas concepções de leitura, para que as mudanças com relação ao ato de ler fossem colocadas em prática nas salas de aula.

$\mathrm{O}$ relato de Beatriz também reforça o entendimento de que, dependendo das estratégias de leitura empregadas nas aulas envolvendo uso de TDC, podese promover leituras parafrásicas e/ou polissêmicas. Essa correlação pode ser evidenciada no excerto abaixo, referente à atividade de pós-leitura (produção e apresentação de propaganda). 
Beatriz: Pessoal! Vamos começar a apresentação? [...] grupo 1 pode falar sobre o fone de vocês?

Aluno 11 (representante do grupo 1): A gente está vendendo o headphone: "cada vez mais popular, não agride o aparelho auditivo, melhor isolamento acústico, apresenta tecnologia noise cancelling, design avançado com várias cores, agora com modelo que não ocupa muito espaço.

Beatriz: Ok, muito bem, vocês foram criativos! Só quero discutir uns pontos com vocês, ok? Lá no texto fala "melhor isolamento acústico, evidenciamos a percepção de graves e agudos permitindo ouvir música com grande fidelidade em volume baixo". O que são sons graves e agudos?

Aluno 5: Altura.

Aluno 2: Frequência menor e maior.

Beatriz: Tá, na frequência maior o que acontece?

Aluno 2: É de som agudo.

Beatriz: É e são sons altos né? Então devido à frequência, o fone tem um melhor isolamentos acústico que permite que a gente note estes diferentes tipos de frequência através dos sons graves e agudos [...]. (Trechos da aula de Beatriz em 28/11/14)

No excerto acima, de um lado, pode-se verificar que a estratégia de pós-leitura adotada por Beatriz permitiu que os alunos explicitassem suas múltiplas interpretações sobre o TDC na propaganda. Dessa forma, a propaganda é o resultado da leitura crítica [50] dos membros do grupo que, na negociação coletiva, decidiram o que deveria ser dito na propaganda, de modo a divulgar o produto, levando em consideração algumas características específicas do fone in-ear abordadas no TDC. Por outro lado, é importante destacar que Beatriz percebeu certos pontos frágeis na propaganda do grupo 1 (relação entre frequência e altura do som) e que mereciam ser aprofundados; portanto, utilizou trechos do texto para se certificar das conexões corretas do ponto de vista científico entre as informações do TDC e o conteúdo de Física.

Durante as apresentações, pôde-se constatar que os quatro grupos realizaram leitura- texto-pretexto e que Beatriz pôde não ter percebido naquele momento da aula, mas a atividade proposta propiciou a intertextualidade. Em outras palavras, os alunos discutiram entre si as informações apresentadas no TDC, as relações entre o TDC e o conteúdo de acústica estudado, outros textos lidos, relembraram propagandas vistas na televisão e comentaram sobre suas próprias experiências enquanto usuários desses dispositivos. Essas histórias de leitura e de vida dos alunos foram consideradas para confeccionar as propagandas dos fones de ouvido.

Pode-se inferir que nessa aula Beatriz valorizou as leituras parafrásicas e as polissêmicas, privilegiou o modo de leitura-texto-pretexto e o discurso apropriado por ela em aula tendeu ao polêmico. No que tange à função do TDC assumida, foi impossível identificar apenas uma das cinco possíveis categorizadas por Ribeiro e Kawamura [18], pois elas foram trabalhadas simultaneamente no contexto dessa aula.

\section{Aula 2-AE-Mariana}

A atividade com o TDC "Para ouvir melhor" foi realizada por Mariana nos dias 27 e 28/11/14 e contou com a participação de 17 alunos. As aulas com o referido TDC contemplaram as seguintes etapas:

Pré-leitura (27/11/14, 20 minutos) - os alunos responderão as questões: 1) Você usa fones de ouvido? Com que frequência? 2) $O$ que você leva em consideração ao comprar um fone de ouvido? 3) Você acha que o uso de fones de ouvido é prejudicial à saúde auditiva? Justifique. [...]. Será feita a discussão destas questões com os alunos, na sequência será entregue o texto "Para ouvir melhor".

Durante a leitura (realizada em casa) será solicitado que eles leiam o texto e respondam as seguintes questões: 1) Explique como a onda sonora chega até nossos ouvidos? 2) Qual é a natureza e qual é a direção de propagação das ondas sonoras? 3) Dos fones de ouvido descritos no texto, qual você compraria? Justifique [...].

Pós-leitura (28/11/14, 45 minutos) - será realizada a discussão do TDC (questões realizadas na etapa de durante a leitura e trechos pré-selecionados). Após esta etapa os alunos serão orientados a organizarem-se em grupos e elaborar um diagrama. (Mariana em seu plano de aula-25/11/14)

Mariana descreve em seu diário que nos dias consecutivos em que essa atividade com TDC foi desenvolvida em sala de aula, houve a participação maciça dos alunos. Ainda, que durante a discussão do TDC em aula, foram utilizadas questões propostas na 
etapa de durante a leitura, dúvidas/ou questões colocadas pelos alunos e trechos do TDC previamente selecionados por ela. Também, a licencianda relatou que atendo a curiosidade dos alunos, utilizou um texto de apoio e o livro didático adotado pela escola para complementar as informações do TDC.

\begin{abstract}
[...] após o relato de um dos alunos: "tenho problema de audição no ouvido direito por que moro perto de um local onde ocorrem muitas construções". Os alunos manifestaram curiosidade em saber a intensidade e o tempo de máximo que uma pessoa pode ficar exposta a determinada fonte sonora (sem causar danos à saúde auditiva). Para fazer esta discussão, orientei os alunos a pesquisarem no LD [livro didático] e no texto de apoio alguns exemplos de intensidades emitidas por fontes sonoras distintas e seus respectivos tempos máximos de exposição [...].
\end{abstract} (Mariana em seu DPP-04/12/14)

A forma como Mariana conduziu esse momento da discussão demonstra que a licencianda percebeu que o TDC é um material complementar ao livro didático e sem fins didáticos [5,7,8,13 15], cabendo ao professor avaliar se há ou não necessidade de complementar as informações do TDC, com o auxílio de outra(s) fonte(s) de informação. Assim, percebese que houve uma mudança significativa acerca da concepção de leitura apresentada por Mariana na pré-regência. Naquela ocasião, ela acreditava que os sentidos estavam inscritos no texto, algo que mudou no decorrer das sucessivas implementações das atividades com TDC no período de regência.

Com base na análise dos registros dessa aula, pode-se inferir que Mariana valorizou as leituras parafrásicas e as polissêmicas. Isso fica evidente quando se analisam as questões propostas nos distintos momentos da leitura, bem como nos trechos utilizados por ela para discutir o TDC e promover as conexões entre o texto e conteúdo. Mariana relata em seu diário que, além da discussão da conceituação Física necessária ao entendimento das informações presentes no TDC, também foram contemplados na discussão aspectos relacionados ao uso, às escolhas, às vantagens e às desvantagens dos diferentes modelos de fone de ouvido. Nesse sentido, Mariana comenta em seu diário:

[...] a discussão acerca do uso de fones de ouvido, foi de extrema relevância, pois, os alunos refletiram sobre seus hábitos e atitudes, bem como, perceberam a aplicabilidade do conteúdo de ondas sonoras em seu dia a dia. [...] esta atividade possibilitou contextualizar o conhecimento científico e com base neste discutir aspectos relacionados ao uso, escolha e funcionamento do fone de ouvido [...] conscientizou-se os alunos de que o uso inadequado desse dispositivo pode provocar lesões ao aparelho auditivo [...]. (Mariana em seu DPP-04/12/14)

Com relação aos oito diagramas produzidos e apresentados pelos grupos de alunos, na etapa de pós-leitura, foram verificadas a realização de leituras parafrásicas (quatro grupos sintetizaram as características de fones in-ear, earpad e headphone que constavam no TDC) e polissêmicas (quatro grupos realizaram uma leitura crítica sobre as informações do TDC ou apresentaram relações entre o TDC e leituras realizadas anteriormente). Portanto, tem-se mais um exemplo que reforça o entendimento de que, dependendo da estratégia de leitura escolhida e empregada nas aulas envolvendo uso de TDC, podem-se promover leituras parafrásicas e/ou polissêmicas.

Somando-se ao que vem sendo exposto, é possível inferir que Mariana privilegiou o modo de leituratexto-pretexto e o discurso apropriado por ela em aula tendeu ao polêmico. No que se refere à função do TDC assumida, foi impossível identificar apenas uma das cinco possíveis tipologias propostas por Ribeiro e Kawamura [18, pois no contexto dessas aulas elas foram contempladas em sua totalidade.

É possível constatar que Mariana utiliza uma metodologia de ensino muito próxima à desenvolvida por Beatriz. No entanto, é extremamente importante enfatizar que um mesmo texto pode gerar interpretações múltiplas por distintos sujeitos leitores, fato comprovado nas últimas aulas da regência que envolveram o uso do mesmo TDC explorado de formas distintas pelas licenciandas. Isso significa dizer que os sentidos atribuídos ao mesmo texto e os conteúdos de Física trabalhados a partir dele foram valorizados de forma distinta por cada uma delas. Além disso, durante as execuções dessas aulas, as licenciandas utilizaram diferentes estratégias de leitura para suscitar discussões sobre as múltiplas interpretações do TDC feitas pelos alunos, estabelecer conexões entre os conteúdos físicos (qualidades fisiológicas do som que haviam sido trabalhadas em aula) e os aspectos relacionados ao entendimento 
do funcionamento e/ou uso e escolha dos fones de ouvido. Entretanto, Mariana parece ter enfatizado de maneira mais contundente a conscientização dos alunos sobre o uso indevido e excessivo deste tipo de dispositivo.

Diante disso, pode-se inferir que, nas aulas com TDC ministradas por Beatriz e Mariana em suas regências, foram valorizadas as leituras polissêmicas, sendo o texto-pretexto o modo de leitura exercido e o discurso apropriado pelas licenciandas tendeu ao polêmico. No que tange à função do TDC assumida, é possível inferir que as cinco categorizadas por Ribeiro e Kawamura [18] acabaram por se aglutinar no contexto dessa aula. Nessa perspectiva, observou-se que o TDC favoreceu o desenvolvimento de habilidades relacionadas às expressões oral e escrita dos alunos (elaboração das propagandas e dos diagramas), possibilitou o contato com informações atualizadas sobre ciência e tecnologia, potencializou a contextualização - que é a articulação entre o conteúdo de Física e o cotidiano do aluno (relações entre a acústica e o funcionamento, uso e escolha dos fones de ouvido), despertou o interesse, motivou novas leituras e gerou atitudes e sentimentos nos sujeitos-leitores (curiosidade, emoção, etc.).

Somando-se a isso, destaca-se que a parceria colaborativa entre os sujeitos desta pesquisa, permitiu que a pesquisadora pudesse acompanhar como se deu o "processo das leituras de TDC feitas pelas licenciandas" e o "processo das leituras de TDC realizadas pelos estudantes do ensino médio" nos períodos de pré-regência e regência. Em função disso, a pesquisadora pôde: orientar e supervisionar as licenciandas durante o processo de elaboração e de implementação das atividades de ensino envolvendo TDC; acompanhar as evoluções delas com relação às leituras, modos de leitura, sentidos atribuídos aos TDC e aos conteúdos de Física trabalhados a partir destes textos em sala de aula; observar como a postura de leitura adotada pelas licenciandas nas regências de estágio influenciou nas leituras, modos de leitura, sentidos atribuídos aos TDC e aos conteúdos de Física por parte dos alunos do ensino médio.

Ao término do ESEF III, Mariana e Beatriz avaliaram as práticas de leitura com TDC desenvolvidas no estágio supervisionado. A título de exemplo, traz-se o depoimento de Mariana que, sucintamente, apresenta as principais mudanças na postura de leitura enfatizadas por ambas. Mariana relata:"[...] hoje posso dizer que as atividades com TDC contribuíram para minha formação pessoal e profissional, percebi que o TDC [...] quando associado as estratégias de leitura pode despertar o gosto pela leitura sobre ciência, tecnologia e favorece as relações com os conteúdos [...]. Passei a usar as estratégias nas minhas leituras e estou fazendo um banco de textos que leio na internet e que posso utilizá-los no futuro $[\ldots] "$ ".

Por fim, acredita-se que o depoimento de Mariana, somado aos resultados anteriormente apresentados, resumem não apenas as contribuições da pesquisa para a formação das professoras leitoras, mas vai além, pois fornecem subsídios para outras pesquisas com foco na questão da leitura na formação de professores de Ciências Naturais.

\section{Considerações finais}

O presente estudo contemplou a discussão acerca dos tipos de leituras, modos de leituras e funções atribuídas aos TDC, por licenciandas, durante seus estágios de pré-regência e regência. Nesta direção, ao comparar os resultados das análises das aulas ministradas por Beatriz e Mariana em suas pré-regências e regências de estágio, é possível inferir, com base em indícios concretos, que houve um deslocamento dos sentidos atribuídos aos TDC. Isso porque nas regências foram valorizadas as leituras polissêmicas, sendo o texto-pretexto o modo de leitura exercido nas aulas e o discurso apropriado pelas licenciandas tendeu ao polêmico. Também, percebeu-se que a função atribuída aos TDC nas pré-regências foi a de ensinar física, ao passo que, nas regências de estágio, as funções atribuídas foram ampliadas, pois essas atividades favoreceram o desenvolvimento de habilidades relacionadas às expressões oral e escrita dos alunos, potencializaram a articulação entre o conteúdo de Física e o cotidiano do aluno, motivaram novas leituras e geraram atitudes nos alunos. Nesse sentido, reitera-se que as atividades de ensino de Física - TDC associados às estratégias de leitura, desenvolvidas pelas licenciandas no estágio supervisionado são de caráter inovador e, portanto, superam as práticas pontuais de leitura de TDC que vem sendo desenvolvidas e relatadas por pesquisadores da área de Educação em Ciências.

Nas aulas com TDC desenvolvidas nos estágios de regência, observou-se que as estratégias de leitura empregadas em sala de aula pelas licenciandas 
cumpriram seus principais objetivos, ou seja, promover as discussões sobre as múltiplas interpretações dos TDC e estabelecer conexões entre o texto e o conteúdo, algo que não aconteceu nas pré-regências. Nesse particular, pode-se observar nas aulas de Beatriz e de Mariana que o funcionamento das leituras de TDC esteve diretamente relacionado às estratégias de leitura empregadas nos distintos momentos da leitura (atividades propostas na etapa de pré/durante/pós-leitura). Assim, as estratégias de leitura utilizadas pelas licenciandas influenciaram nos sentidos atribuídos aos TDC pelos alunos, fato que foi observado nas regências de estágio.

É relevante destacar que, a pareceria colaborativa estabelecida entre os sujeitos participantes no contexto no estágio profissional em Física, permitiu à pesquisadora acompanhar como aconteceu o "processo de leitura de TDC, a elaboração e a implementação das atividades de ensino envolvendo TDC associados à estratégias de leitura" pelas licenciandas. Assim, foi possível acompanhar os avanços das licenciandas com relação às leituras, modos de leitura, sentidos atribuídos aos TDC e aos conteúdos de física trabalhados a partir destes textos em sala de aula, bem como, observaram-se as evoluções dos estudantes do ensino médio em relação à leitura, à escrita, à interpretação, à argumentação e aos sentidos atribuídos ao conteúdo científico e ao TDC em cada etapa de leitura. Assim, foi possível acompanhar as aprendizagens das licenciandas e de seus alunos, ao longo das sucessivas e periódicas atividades com TDC implementadas nas aulas de Física.

A proposta de uso de TDC associado às estratégias de leitura em aulas de Física, mostrou ser um caminho possível para a valorização das leituras polissêmicas, além de ser uma possível maneira de promover as conexões entre o conteúdo científico e temas relacionados ao cotidiano, à ciência e à tecnologia. Além de potencializar o desenvolvimento de habilidades relacionadas à leitura e escrita, favorecendo a formação dos sujeitos-leitores no contexto da formação inicial de professores e na escola.

Por fim, acredita-se que os resultados obtidos no contexto do estágio profissional em Física, envolvendo o uso de TDC associado à atividades estratégicas de leitura, contribuem significativamente para fomentar novas debates sobre a questão da leitura e da escrita no contexto da formação inicial de professores de Ciências Naturais e da Escola. Assim, como perspectivas para trabalhos futuros, sugere-se que seja investigado se e como os professores trabalham em suas disciplinas a leitura de e a escrita sobre materiais de DC.

\section{Referências}

[1] L.M.S. Zamboni, Cientistas, Jornalistas e a Divulgação Científica: Subjetividade e Heterogeneidade no Discurso da Divulgação Científica (Autores Associados, Campinas, 2001).

[2] T.G. Nascimento e S. Cassiani, Revista Electrónica de Enseñanza de las Ciencias 8, 745 (2009).

[3] A.C. da Silva e M.J.P.M. de Almeida, Alexandria: Revista de Educação em Ciência e Tecnologia 7, 49 (2014).

[4] D. Correia, M.A. Bolfe e I.P.S. Sauerwein, Caderno Brasileiro de Ensino de Física 33, 556 (2016).

[5] S. Salém e M.R.D. Kawamura, in: Anais do V Encontro de Pesquisa em Ensino de Física, Águas de Lindóia, 1996.

[6] J.A. da Silva e M.R.D. Kawamura, Caderno Brasileiro de Ensino de Física 18, 316 (2001).

[7] A.M.C. Maffia, S.R. Cruz, M.L.S. Dias e A.R.C. Braúna, in: Anais do VIII Encontro Perspectivas do Ensino de Biologia, São Paulo, 2002.

[8] E.A. Terrazzan e M. Gabana, in: Anais do IV Encontro Nacional de Pesquisa em Educação em Ciências, Bauru, 2003.

[9] I. Martins, T.G. Nascimento e T. de Abreu, Investigações em Ensino de Ciências 9, 95 (2004).

[10] H.C. da Silva e M.J.P.M. de Almeida, Revista Electrónica de Enseñanza de las Ciencias 4, 155 (2005).

[11] L.N. de Abreu, L. Massi e S.L. Queiroz, in: Anais do VI Encontro Nacional de Pesquisa em Educação em Ciências, Florianópolis, 2007.

[12] T.M.C. Menegat, L. Clement e E.A. Terrazzan, in: Anais do VI Encontro Nacional de Pesquisa em Educação em Ciências, Florianópolis, 2007.

[13] L.N.A. Ferreira e S.L. Queiroz, Alexandria Revista de Educação em Ciência e Tecnologia 5, 3 (2012).

[14] M.R. Rocha, Revista Acta Scientia 14, 132 (2012).

[15] M. Zanotello e M.J.P.M. de Almeida, Revista Ensaio 15, 113 (2013).

[16] A.C. da Silva, M.J.P.M. de Almeida e M.L. Hallack, Caderno Brasileiro de Ensino de Física 32, 53 (2015).

[17] I. Martins, M. Cassab e M.B. Rocha, in: Anais do III Encontro Nacional de Pesquisa em Educação em Ciências, Atibaia, 2001.

[18] R.A. Ribeiro e M.R.D. Kawamura, in: Anais do $X$ Encontro Nacional de Pesquisa em Ensino de Fúsica, Londrina, 2006.

[19] L.N.A. Ferreira e S.L. Queiroz, Ciência \& Educação 17, 541 (2011). 
[20] L.N.A. Ferreira e S.L. Queiroz, Revista Brasileira de Pesquisa em Educação em Ciências 12, 139 (2012).

[21] L.N.A. Ferreira e S.L. Queiroz, Alexandria Revista de Educação em Ciência e Tecnologia 5, 3 (2012).

[22] L.N.A. Ferreira e S.L. Queiroz, Ciência \& Ensino 3, 32 (2014).

[23] T.G. Nascimento e M.F.A. Rezende Junior, Revista Brasileira de Pesquisa em Educação em Ciências 10, 1 (2010).

[24] R.H.A. Dias e M.J.P.M. de Almeida, Revista Brasileira de Ensino de Física 31, 4401 (2009).

[25] R.H.A. Dias e M.J.P.M. de Almeida, Revista Ensaio 12, 51 (2010).

[26] M.C.A. Lima e M.J.P.M. de Almeida, Revista Brasileira de Ensino de Física 34, 4401 (2012).

[27] M.J.P.M. de Almeida e H.C. da Silva, in: Anais do VI Encontro de Pesquisa em Ensino de Física, Florianópolis, 1998.

[28] I. Solé,Estratégia de Leitura (Artmed, Porto Alegre, 1998).

[29] S.C. de Souza e T.G. Nascimento, Pro-Posições 17, 105 (2006).

[30] T.M.K. Rösing, A Formação do Professor e a Questão da Leitura (UPF Editora, Passo Fundo, 2003).

[31] E.P. Orlandi, Discurso e Leitura (Cortez, São Paulo, 1993), $2^{\mathrm{a}}$ ed.

[32] E.P. Orlandi,Análise de Discurso: Princípios e Procedimentos (Pontes, Campinas, 2002).

[33] E.P. Orlandi, A linguagem e seu Funcionamento: As Formas do Discurso (Editora Brasiliense, São Paulo, 1983).

[34] E.P. Orlandi, Interpretação: Autoria, Leitura e Efeitos do Trabalho Simbólico (Vozes, Petrópolis, 1996), $2^{\mathrm{a}}$ ed.

[35] E.P. Orlandi, Leitura: Teoria \& Prática 3, 7 (1984).

[36] I.B. Andrade e I. Martins, Investigações em Ensino de Ciências 11, 1 (2006).

[37] J.W. Geraldi, Leitura: Teoria \& Prática 3, 25 (1984).

[38] S.C. de Souza, Leitura e Fotossíntese: Proposta de Ensino Numa Abordagem Cultural. Tese de Doutorado, UNICAMP, 2000.

[39] J.G. Teixeira Júnior e R.M.G. da Silva, Química Nova 30, 1365 (2007).

[40] R.C. Bogdan e S.K. Biklen, Investigação Qualitativa em Educação: Uma Introdução à Teoria e aos Métodos (Porto Editora, Portugal, 1994).

[41] C.R. Brandão, Pesquisa Participante (Brasiliense, São Paulo, 2006).

[42] M. Thiollent, Metodologia da Pesquisa-ação (Cortez, São Paulo, 2008).

[43] M. Souza e R. Paupitz, Revista Ciência Hoje 299, 32 (2012).

[44] J. Manfrin e D. Macedo, Revista Veja, 96 (2014).

[45] O. Alves, Revista Ciência Hoje 45, 10 (2010).
[46] M.A. Zabalza, Diários de Aula: Contributo para o Estudo dos Dilemas Práticos dos Professores (Porto Editora, Portugal, 1994).

[47] R. Porlán e J. Martín, El diário del Professor: Un Recurso para la Investigación en el Aula (Díada Editora, Espanha, 1997).

[48] R. Hess, in: Tempos, Narrativas e Ficções: A Invenção de $S i$, editado por E.C. Souza, e M.H.M.B. Abrahão (EDIPUCRS, Porto Alegre, 2006), p. 89.

[49] C. Gauthier, S. Martineau, J.F. Desbiens, A. Malo e D. Simard, Por Uma Teoria da Pedagogia. Pesquisas Contemporâneas Sobre o Saber Docente (Editora Unijuí, Ijuí, 1998).

[50] W.E. Francisco Junior, Revista de Investigação em Ensino de Ciências 16, 161 (2011). 